Revista Aspas

ppgac - USP

Desenho de Pesquisa

\title{
ALGUMAS INTERSEÇÕES METODOLÓGICAS NO DESENVOLVIMENTO DO TRAJE CÊNICO
}

\section{SOME METHODOLOGICAL INTERSECTIONS IN THE DEVELOPMENT OF SCENIC COSTUME}

\section{ALGUNAS INTERSECCIONES METODOLÓGICAS EN EL DESARROLLO DEL DISFRAZ ESCÉNICO}

\author{
Isac Sobrinho
}

Isac Sobrinho

Formou-se em design moda pela universidade federal do Ceará em 2021, desenvolve pesquisas na área de figurinagem, caracterização de cena, bem como metodologias de criação de traje e figurino dramatúrgico. É designer de figurino e ministra curso sobre o tema em instituições públicas na capital de

Fortaleza. Desenvolve projetos de figurino para as áreas de teatro, dança, performance e audiovisual. 


\section{Algumas interseções metodológicas no desenvolvimento do traje cênico}

\section{Resumo}

Este artigo revisita ações técnicas para o desenvolvimento de figurino a partir de três abordagens metodológicas diferentes, visando observar semelhanças e convergências entre elas. Objetiva assim, expandir a discussão sobre métodos de criação de traje cênico, contribuindo para fomentar novas pesquisas sobre metodologia de figurinagem. Para este processo de investigação, foi utilizada pesquisa exploratória e análises, delineadas a partir de material bibliográfico e apoiadas pela observação participante.

Palavras-chave: desenvolvimento, figurino, metodologias.

\section{Abstract}

This article revisits technical actions for costume development from three different methodological approaches, aiming to observe similarities and convergences between them. Thus, it aims to expand the discussion on methods of creating scenic costumes, contributing to foster new research on costume methodology. For this investigation process, exploratory research and analysis were used, delineated from bibliographic material and supported by participant observation.

Keywords: development, costumes, methodologies.

\section{Resumen}

Este artículo revisa las acciones técnicas para el desarrollo del vestuario desde tres enfoques metodológicos diferentes, con el objetivo de observar similitudes y convergencias entre ellos. De esta forma, pretende ampliar la discusión sobre los métodos de creación de vestuario escénico, contribuyendo a fomentar nuevas investigaciones sobre la metodología del vestuario. Para este proceso de investigación se utilizó investigación exploratoria y análisis, delineados a partir de material bibliográfico y apoyados por la observación participante.

Palabras clave: desarrollo, vestuario, metodologías. 


\section{Introdução}

É cada vez mais entendido que as visualidades da cena são fundamentais para um melhor entendimento do espectador acerca da obra. Nesse sentido, o mercado cênico vem optando por profissionais que compreendem a importância das potentes contribuições dos elementos visuais para a encenação. Dentre esses elementos, o figurino desempenha lugar de destaque, uma vez que é o recurso visual material mais próximo ao corpo do ator (NOBRE SOBRINHO, 2020, p.34).

O figurino ou traje cênico é analisado a partir de suas materialidades, que poderá vir a ser o conjunto de peças do vestuário e seus acessórios tais como: roupas, joias, chapéus, bolsas, calçados e etc. (LOPES,2010, p.12). Esse conjunto material fornece suporte para a construção da personagem, pois vem a ser o objeto palpável mais próximo ao corpo do ator. É através dos trajes que os artistas podem encontrar características para os papeis que representarão (NOBRE SOBRINHO, 2020, p 34)

A função dos trajes cênicos deve ser a de comunicar, é um elo informativo partindo do espetáculo em direção ao espectador (NOBRE SOBRINHO, 2020, p 35). As autoras Leite e Guerra (2002, p 62) afirmam que "o figurino representa um forte componente na construção do espetáculo, seja no cinema, no teatro ou na televisão. Além de vestir os artistas, respalda a história narrada como elemento comunicador [...]"

Para uma comunicação eficaz é necessária uma investigação de uma série de variáveis que se conectam com esse elemento. No entanto, percebemos que os profissionais da área de figurinagem adotam técnicas de desenvolvimento particulares. Já as reflexões cientificas envolvendo o campo do traje de cena, inclinam-se, com frequência, as descrições de projetos específicos tornando difícil a replicação do método. Esse fato compromete as pesquisas voltadas às metodologias de desenvolvimento de figurino, que são escassas comparadas à demanda de produção. Ramos (2012) afirma que:

Um reflexo dessa conjuntura é a falta de material bibliográfico produzido em nosso país específico ao campo do figurino. [...] Considero ainda que não haja sequer um consenso entre os pesquisadores de figurino quanto à terminologia relativa a essa 
disciplina, realidade que [...] dificulta muito as pesquisas. (RAMOS, 2012, p.89)

Compreendendo essa problemática, procuramos nessa pesquisa investigar ações técnicas de desenvolvimento de figurino relacionadas a encenação artística que sejam possíveis de disseminação. Através de pesquisa exploratória a partir de material bibliográfico, este estudo foi desenvolvido tendo como recorte propostas metodológicas de três abordagens sistemáticas: Viana apud Pereira (2012); Gonçalves e Epifânio (2012); Iglécio e Italiano (2012), as quais serão apresentadas e analisadas a partir do método comparativo. Construiremos uma tabela organizacional como meio de identificar possíveis procedimento análogos, almejando sintetizar estas ações similares. Recorremos ainda a observação participante como meio de interpretação dos eixos convergentes.

Acreditamos, ainda, que este trabalho possa contribuir com a expansão de discussões acerca de procedimentos técnicos na criação de trajes cênicos, uma vez que compila algumas metodologias e as apresenta de forma objetiva.

\section{Método 1- Viana apud Pereira (2012)}

O primeiro método analisado parte de uma citação de Dalmir Pereira (2012), que pode servir como direcionamento para figurinistas. Esta menção é referente a conteúdos didáticos de aulas de Fausto Viana. Com isso Pereira aponta que:

Os elementos que compõem o trabalho do figurinista estão divididos em três grupos: no grupo 1- em primeiro lugar estão às opções estéticas do espetáculo e o estilo da direção e toda equipe precisa destas diretrizes para trabalhar. Em segundo está o impacto visual e em terceiro o recurso financeiro (a quantia de recursos financeiros disponíveis para o figurino, para que não haja surpresas e inviabilidades). No grupo 2 estão os itens (regras ou observações) que devem ser checados: em primeiro lugar as indicações do texto ou referências temáticas quando não houver literatura dramática. Em segundo e terceiro estão à iluminação e o cenário. Para que se possa estudar a relação do traje com a luz, as cores, as formas do espaço e devidas especificações. Mesmo que seja um projeto da iluminação e da cenografia, pois o grupo deve trabalhar em conjunto somando as particularidades de cada área. No grupo 3 estão os 
aspectos que o traje pode revelar em cena: espaço-localização espacial e geográfica, tempo- período histórico, clima e época do ano, hora do dia e ocasião, idade, sexo, ocupação, posição social e atividade e fatores psicológicos. (PEREIRA, 2012, p.9).

A partir da citação construímos o seguinte quadro síntese.

Figura 1 - Quadro sintético para o método de Viana apud Pereira (2012)

1-Opções estéticas

-Estilo de direção

2- Impacto visual

Informações gerais

- Indicações no texto

2- Iluminação

3-Cenário

Relações entre os demais elementos cênicos

Aspectos que o figurino

pode revelar em cena

(cor, textura, espaço,

tempo, clima, idade)

Autonomia do setor de figurino e

construções das personagens

Fonte: Autor baseado nas informações de Viana apud Pereira (2012, p.9)

Compreendemos que no grupo 1- as opções estéticas: estão relacionadas a concepção de materialização do traje e a aproximação ou distanciamento da aparência realista. Podemos deduzir que nesse grupo, ainda, seria informado em que linguagem cênica estaria inserida o projeto, bem como suas determinações. Quanto ao estilo de direção, supomos que poderá se relacionar com as poéticas subjetivas da direção geral e optar por obra colaborativa. "Uma proposta muito comum hoje em dia é a criação do 'texto', em conjunto, com a equipe toda trabalhando, propondo, criando...É uma dramaturgia coletiva, que não necessariamente vai terminar em um texto formal [...]" (VIANA; PEREIRA, 2015, p.17). Já os impactos visuais estariam relacionados com o grau de relevância dos aspectos visuais em cena, tais como iluminação, cenário e figurino por exemplo. No que diz respeito aos recursos financeiros, concordamos que se trata de orçamentos disponíveis para o projeto e a verba destinada aos setores. 
No grupo 2 é onde se observa algumas regras e direcionamentos contidos no texto ou discutidas. Isso se dá mediante a leitura do texto, pois nele se encontram descritas as orientações prévias sobre a cena (explicações feitas por autores antes das falas), bem como apontamentos nos próprios diálogos das personagens. Há dentro desse grupo, ainda, a necessidade de se pensar no figurino e sua interação com a iluminação: se a iluminação se aproxima mais da luz natural, que cores a iluminação realçaria ou não e em terceiro a interação do figurino com o espaço cênico (teatro de rua, caixa cênica ou outros).

Já no grupo 3, verificamos que é onde se considera a comunicação dos personagens com o espetáculo e com o espectador, revelando informações necessárias para a identificação e diferenciação da personagem em relação as demais. É aqui que os estudos sobre cor, textura, silhueta ou outros elementos do figurino podem se embasar.

Foi possível entender, a partir da citação de Pereira (2012, p.9), que as orientações técnicas são distribuídas em três grupos e suas informações processuais são especificas para cada um. Portanto, notamos que os grupos podem ser delimitados da seguinte maneira: Grupo 1 (informações gerais sobre o espetáculo, grupo 2 (relações com o texto, cenário e iluminação) e no grupo 3 (ações especificas para a criação da imagem das personagens).

Notamos, ainda, que dentro dos grupos 1 e 2 existe uma hierarquia de ações técnicas, ou seja, algumas ações metodológicas e informacionais são prioritárias, ou mais relevantes em consideração as outras. Assim, temos no grupo 1: as opções estéticas poderão ser mais relevantes que os impactos visuais e esta, por sua vez, mais importante que os recursos financeiros. Já no grupo 2: as indicações no texto devem ser primeiramente observadas, em seguida as relações com o setor iluminação e finalmente as relações com o setor de cenografia. 


\section{Método 2 - Gonçalves e Epifânio (2012)}

Para Gonçalves e Epifânio (2012) as atividades seguem em etapas: o préprojeto, o projeto, a pré-produção e a produção. Como mostra a figura 2:

Figura 2 - Quando de etapas do método Gonçalves e Epifânio (2012)

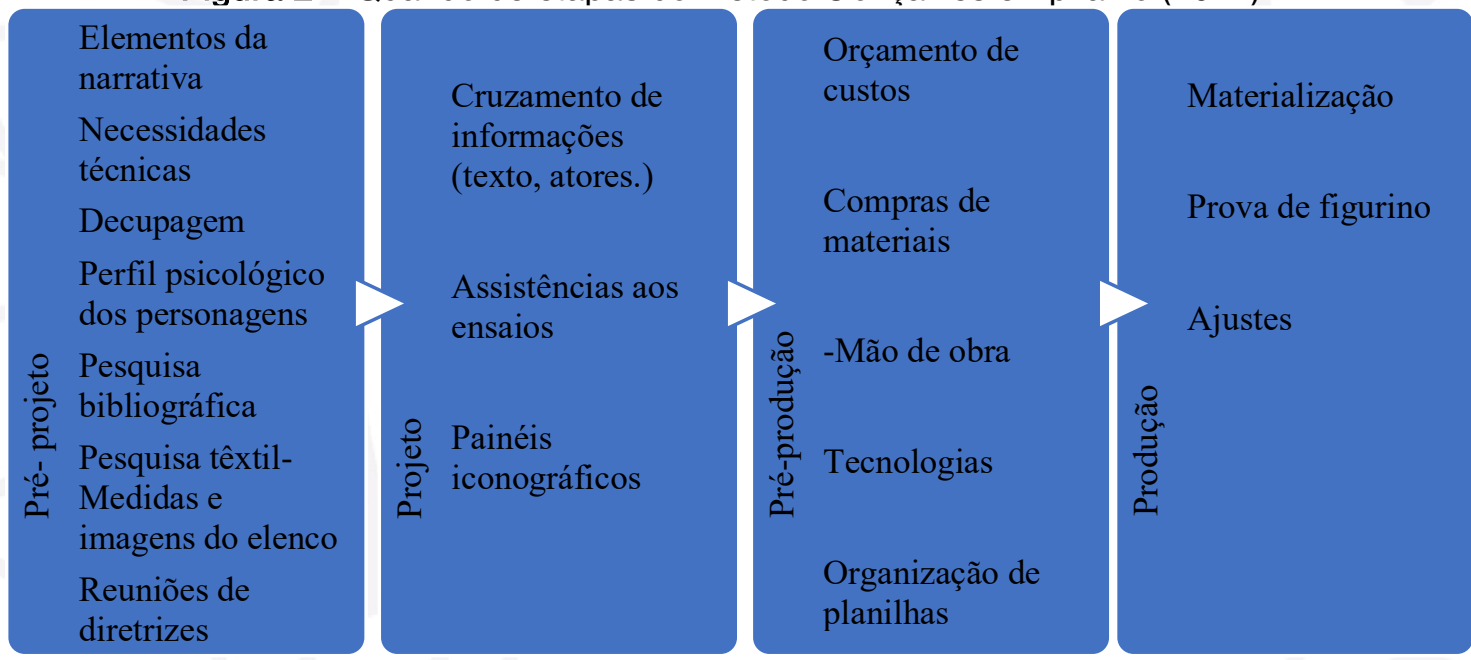

Fonte: Autor baseados nas informações de Gonçalves e Epifânio (2012)

No pré-projeto é onde se estabelece o primeiro contato com o texto. É nele que poderá ser observado questões relativas aos elementos da narrativa ${ }^{1}$ : tempo espaço e personagem, termos técnicos referentes a cada linguagem específica, tempos de trocas de uma cena para outra, necessidades cênicas, percurso dos atores previamente citados no texto, além do estilo do espetáculo. Poderá também ser proposto junto à direção um resumo de cada cena descrita no texto ou roteiro citando os espaços e tempo, roupas, acessórios, movimentação cênica. A esta ação pode ser chamada de decupagem cena à cena.

O perfil psicológico das personagens já pode surgir a partir desse contato com a direção e com os demais profissionais envolvidos na obra. Parte-se, então, para as pesquisas bibliográficas, visuais e têxteis que poderá contribuir para a materialização dos trajes cênicos. É nessa etapa que são tiradas as medidas corporais e as fotografias dos atores, assim como suas

${ }^{1}$ Cf. $\cos T A(2002)$ 
"capacidades individuais em relação à interpretação e expressão corporal" (GONÇALVES; EPIFÂNIO, 2012, p.3), que devem ser observadas mediante os ensaios ou vídeos dos mesmos. Essa etapa é importante para organização de informações. Os autores complementam ainda que o montante orçamentário também deverá ser incluído nessa etapa para que nas etapas posteriores possa ser levado em consideração.

$\mathrm{Na}$ etapa de projeto, há um cruzamento de informações entre cada figurino, texto e atores, para isso a participação nos ensaios passa a ser fundamental para nortear a criação do traje. Nessa etapa poderá ser construído painéis iconográficos para cada personagem e figuração geral. A partis disso, parte-se então para novas reuniões para estabelecer se as idealizações estão em sincronia ou se há necessidade de modificações.

A etapa de pré-produção começa a orçar os custos financeiros envolvidos nas etapas anteriores do setor de figurinagem, para em seguida materializar. Relações de beneficiamentos têxteis, compras de materiais, mão de obra e tecnologias disponíveis, assim como o tempo de execução para cada item que possa vir a ser adquirido. Este processo será avaliado e disponibilizado em planilhas e documentos que deverão ser apresentados às equipes de produção executiva. Nesta etapa já pode ser avaliado a possibilidade de vestir personagens a partir de criação hibrida como explica os autores:

\footnotetext{
O desafio de vestir a personagem teatral pode consistir na criação de figurinos originais, a partir de desenhos; na composição a partir de peças adquiridas no mercado varejista ou em brechós, que se verifica principalmente em espetáculos com temática atual; ou ainda, na composição híbrida, onde são mescladas peças compradas prontas com peças criadas especialmente. (GONÇALVES; EPIFÂNIO, 2012, p. 2)
}

Na etapa de produção, põe-se em prática todos os encaminhamentos das etapas anteriores. Para tanto, as informações coletadas nas etapas anteriores devem ser entregues em tempo hábil. Isso facilitará a materialização das peças de roupas que deverão ser utilizadas nos ensaios e, assim, realizar alguns ajustes, caso necessário.

Os autores complementam que essa metodologia se mostrou eficaz em diversos segmentos de produção de figurino, desde obras com dois atores até 
óperas. Gonçalves e Epifânio (2012, p.5), acreditam que uma das possibilidades para a eficiência do método é o registro e organização de uma pasta com as informações processuais e disponível para todo o setor de figurinagem.

\section{Método 3- Iglécio e Italiano (2012)}

As autoras Paula Iglécio e Isabel Italiano (2012) discorrem sobre a metodologia do processo de criação do figurino, a qual foi organizada em etapas conforme descrito a seguir. A metodologia descrita pelas autoras baseou-se nos textos de Rosemary Ingham e Liz Covey²:

1 - Leitura do texto: a primeira leitura tem como objetivo identificar o enredo e onde se inserem os personagens;

2 - Análise do texto: deve-se indicar os principais elementos limitantes e potenciais para os personagens. Inclui-se, aqui, perguntas sobre espaço e tempo, quais são os personagens e suas funções e características. Elaborar uma tabela com as ações e atos transcorridos e suas respectivas participações na cena;

3 - Encontro com diretor: tem por objetivo sanar as dúvidas de cunho prático e estético que servirão para estabelecer as características gerais para a criação do figurino;

4 - Pesquisa de figurino: é onde inicia a coleta de informações imagéticas e bibliográficas. É possível criar fichas com observações sobre o ambiente, história, espaço-tempo nos quais se passa o projeto;

5 - Desenhos preliminares e paleta de cores: onde se desenvolvem os primeiros rabiscos para a apresentação detalhada dos pensamentos do figurinista para o diretor;

6 - Apresentação e discussão com o diretor: nessa etapa são apresentados os resultados da pesquisa imagética e os desenhos para o diretor com o intuito de obter o aval ou possíveis observações;

\footnotetext{
2 INGHAM, Rosemary; COVEY, Liz. The costume designer's handbook, Heinemann Educational Books, Portsmouth, Estados Unidos, 2. Ed., 1992.
} 
7- Finalização dos desenhos.

As autoras ainda afirmam que o mais importante é transmitir as mensagens presentes nos trajes. Devido a isso alguns processos, escolhas criativas e matérias-primas sofrerão alterações no decorrer do percurso de desenvolvimento do projeto, para atender as necessidades comunicacionais estabelecidas entre o espetáculo e a plateia. (IGLÉCIO; ITALIANO, 2012, p.8)

Percebemos que nas ações técnicas discutida pelas autoras, há uma inclinação a uma metodologia linear como pode ser visto na figura 3:

Figura 3 - Quadro sintético de metodologia Iglécio e Italiano (2012)

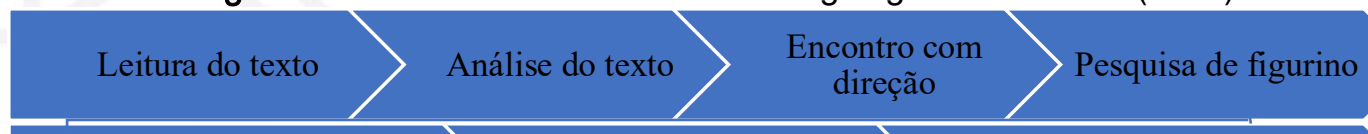

Desenho preliminar e paleta $\left.>\begin{array}{c}\text { Apresentação e discussão } \\ \text { com o diretor }\end{array}\right\rangle$ Finalização dos desenhos

Fonte: Autor baseado nas informações de Iglécio e Italiano (2012)

Iglécio e Italiano (2012, p.8) complementam que, mesmo com o passar do tempo, outros autores desenvolveram metodologias semelhantes e que isso pode ser visto como pouca variação metodológica.

Interseções metodológicas

Ao elaborar uma tabela organizacional, observou-se ações que convergem em eixos como mostra a figura a seguir: 
Figura 6 - Tabela organizacional de ações metodológicas

\begin{tabular}{|c|c|c|}
\hline \multirow[t]{8}{*}{ Eixo 1} & Método 1 & Opções estéticas \\
\hline & Método 1 & Estilo de direção \\
\hline & Método 1 & Impacto visual \\
\hline & Método 1 & Recurso financeiro \\
\hline & Método 2 & Reuniões de diretrizes \\
\hline & Método 2 & Montante orçamentário \\
\hline & Método 3 & Encontro com diretor \\
\hline & Método 3 & Apresentação e discussão com o diretor \\
\hline \multirow[t]{10}{*}{ Eixo 2} & Método 1 & $\begin{array}{l}\text { conexões com os demais elementos cênicos e } \\
\text { suas relações (cenário/iluminação }\end{array}$ \\
\hline & Método 2 & Necessidades técnicas \\
\hline & Método 2 & Pesquisa têxtil \\
\hline & Método 2 & Medidas e imagens do elenco \\
\hline & Método 2 & Mão de obra \\
\hline & Método 2 & Compra de material \\
\hline & Método 2 & Tecnologias \\
\hline & Método 2 & Figurinos híbridos \\
\hline & Método 3 & Desenhos preliminares \\
\hline & Método 2 & Pesquisa bibliográfica \\
\hline \multirow[t]{3}{*}{ Eixo 3} & Método 3 & Pesquisa bibliográfica \\
\hline & Método 3 & Pesquisa Iconográfica \\
\hline & Método 3 & Pesquisa documental e de registro \\
\hline \multirow[t]{7}{*}{ Eixo 4} & Método 1 & Indicações no texto \\
\hline & Método 1 & $\begin{array}{l}\text { Aspectos que o figurino pode revelar em cena } \\
\text { (cor, textura, espaço, tempo, clima, idade) }\end{array}$ \\
\hline & Método 2 & Elementos da narrativa \\
\hline & Método 2 & Decupagem \\
\hline & Método 2 & Perfil psicológico dos personagens \\
\hline & Método 3 & Analise do texto \\
\hline & Método 3 & Leitura do texto \\
\hline
\end{tabular}

Fonte: Autor

Verificamos que as ações semelhantes entre as metodologias pesquisadas, podem ser reagrupadas em 4 eixos temáticos.

No eixo 1, concentramos todas as orientações técnicas que podem ser discutidas com qualquer departamento, isto é: informações gerais sobre o projeto. Sendo assim as opções estéticas, o estilo de direção, o impacto visual da obra, os recursos financeiros disponíveis e as reuniões de direcionamento foram agrupadas nesse bloco, pois são ações técnicas e informativas para todos os departamentos envolvidos na obra.

Já no eixo 2, agregamos atividades que se relacionam com conhecimentos técnicos relativos à execução do figurino, ou seja, todas a ações que sugerem a relação com a materialidade. Neste eixo encontramos 
as necessidades de entendimento sobre a relação do figurino com a iluminação e cenário, pesquisas têxteis, compra de material, relações com o elenco (medidas, fotos, ensaios), mão de obra assistente, outras formas de obtenção de figurino (figurinos híbridos), desenhos projetuais, mapeamento das necessidades técnicas do figurino e etc.

Ao observados o eixo 3, identificamos que existem ações que sugerem, especificamente, os estudos sobre pesquisas teóricas de cunho documental. Estas pesquisas teóricas engloba as bibliográficas, iconográficas e de registro.

Percebemos que as metodologias estudadas atribuem ao texto do espetáculo uma atenção considerável. Devido a isso pudemos organizar o eixo 4 dentro da perspectiva do texto narrativo. Então temos: leitura do texto e suas indicações, elementos da narrativa, decupagem, perfil psicológico das personagens e aspectos que o figurino pode mostrar em cena.

\section{Considerações}

Com este estudo pudemos observar que as metodologias para desenvolvimento de figurino investigadas puderam formar eixos similares: Eixo 1 - orientações gerais do projeto; eixo 2- conhecimentos técnicos para a materialização; eixo 3- pesquisas documentais, bibliográficas e iconográficas e eixo 4- estudo do texto narrativo.

Dentre os eixos identificados o método 3- Iglécio e Italiano, 2012, esteve presente em todos, o que se mostra mais abrangente ou melhor delimitado. No entanto este método se apresenta a partir de etapas, isto é, os procedimentos constituem uma linearidade que nem sempre é possível de se utilizar no desenvolvimento de figurino. Devido a isso a metodologia poderá necessitar de adaptações para satisfazer as necessidades do projeto diversificados como é o caso de espetáculos de direção colaborativa. Identificamos, ainda, que não há descrições de atividades de materializações para os trajes cênicos e que a convergência no eixo 2 (conhecimentos técnicos para a materialização) é referente somente ao desenho dos trajes. 
Por isso, entendemos que o método 3 não expande a reflexão acerca do desenvolvimento do projeto de figurino.

Verificamos que no método 2- Gonçalves e Epifânio, 2012, as ações são descritas em etapas. Neste método há uma maior preponderância no eixo 2 (conhecimentos técnicos para a materialização) com um detalhamento maior das ações técnicas, incluindo descrições sobre conhecimentos acerca de materialização das indumentárias. Sua menor incidência se dá nos eixos 1 (orientações gerais do projeto) e 3 (pesquisas documentais, bibliográficas e iconográficas). Percebemos com isso que este método pode ser adaptado para facilitar a sua replicação.

Quanto ao método 1- Viana apud Pereira, 212, encontra convergência principalmente nos eixos 1 (orientações gerais do projeto), 2(conhecimentos técnicos para a materialização) e eixo 4 (estudo do texto narrativo). Identificamos que este método possui grupos específicos e ações hierárquicas, o que o aproxima das linearidades dos demais métodos apresentados nesse estudo. Percebemos também, que ele não se mostrou convergente dentro do eixo que se relaciona com pesquisas documentais, pois não há qualquer menção a esse tipo de pesquisa na citação elaborada pelo seu autor. Identificamos, também, que este método se mostrou mais amplo e inclusivo para novas perspectivas de criação de espetáculo, comparando-o aos outros dois. Porém, não apresenta informações aprofundadas, devido isso, torna-se dificultosa a replicação das ações por ele sugeridas, abrindo margem para interpretações deturbadas. Com isso, faz-se necessário uma maior investigação acerca deste método para uma melhor elucidação.

Notamos ainda, que no método 1- Viana apud Pereira, 2012, e no método 2 (Gonçalves e Epifânio, 2012, abre margem para uma observação sobre o tipo de linguagem para qual o figurino deverá ser criado, porém nenhum dos métodos citados se aprofunda em descrever que tipos de linguagens seriam essas e se haveria algumas especificidades entre as mesmas.

Com as interseções realizadas, pudemos concluir que houve convergência entre as ações de desenvolvimento de figurino e que foi possível 
relacioná-las em eixos temáticos. São eles : Eixo 1 - orientações gerais do projeto, no qual se obtém informações que não precisam ser específicas do setor de figurinagem, mas que podem vir a determinar escolhas significativas dentro do processo de materialização do traje; eixo 2- conhecimentos técnicos para a materialização, onde são verificados as aptidões técnicas para a criação do figurino, bem como as tecnologias empregadas e as operações envolvidas; eixo 3- pesquisas documentais, bibliográficas e iconográficas, no qual se utiliza de bibliografias, registro e demais documentos e eixo 4- estudo do texto narrativo, que é onde se observa tudo que for significante para a funcionalidade do figurino e sua estética final.

Concluímos, ainda, que estas ações metodológicas se complementam e podem vir a formar uma base de estudo para o desenvolvimento de novas metodologias de criação voltadas para o design de figurino.

\section{Referências}

CASTRO, Marta; COSTA, Nara. Figurino - O traje de cena. IARA - Revista de Moda, Cultura e Arte. São Paulo, 2010. Disponível em:

http://www1.sp.senac.br/hotsites/blogs/revistaiara/wp-

content/uploads/2015/01/05_IARA_vol3_n1_Artigo.pdf acesso em: 1 abr. 2020. COSTA, F. A. D. O figurino como elemento essencial da narrativa. Sessões do imaginário, Porto Alegre, n. 8, agosto 2002.

GONÇALVEZ, Ney Madeira; EPIFANIO, Renata Lamenza. A criação de figurino teatral: entre a teoria e a prática. In: Colóquio de moda, 8.,2012, Rio de Janeiro. IGLESIO, Paula; ITALIANO, Isabel C. O figurinista e o processo de criação de figurino In: Colóquio de moda,8.,2012, Rio de Janeiro.

LEITE, Adriana Sampaio; GUERRA, Lisette. Figurino; uma experiência na televisão. São Paulo: Paz e Terra, 2002.

MARCONNI, Marina de Andrade; LAKATOS, Eva Maria. Fundamentos da metodologia cientifica. 5. ed. Sao Paulo: Atlas, 2003.

NOBRE SOBRINHO, José Isac. Um estudo sobre o desenvolvimento de figurino pela óptica do metaprojeto. Trabalho de conclusão de curso (graduação)Universidade Federal do Ceará. Instituto de cultura e arte, curso design de moda, Fortaleza,2020. 106.f. 
PEREIRA, Dalmir Rogério. Ensaiando sobre traje de cena. In: Colóquio de moda,8.,2012, Rio de Janeiro. ANAIS ELETRÔNICOS. Disponível em:

$<$ http://www.coloquiomoda.com.br/coloquio2017/anais/anais/edicoes/8-Coloquio-deModa_2012/GT09/COMUNICACAO-

ORAL/102910_Ensaiando_sobre_trajes_de_cena.pdf.> Acesso em :04 mar. 2020. VIANA, Fausto; PEREIRA, Dalmir Rogério. Figurino e cenografia para iniciantes. São Paulo: Estação das Letras e Cores, 2015. 